\title{
Experimental survey on off-stream floodplain storages: first results
}

\author{
F. De Martino ${ }^{1} \&$ F. De Paola ${ }^{2}$ \\ ${ }^{I}$ ARCADIS, Agenzia Regionale CAmpana DIfesa Suolo, Italy \\ ${ }^{2}$ Department of Hydraulic, Geotechnical and Environmental \\ Engineering, University of Naples FEDERICO II, Italy
}

\begin{abstract}
In Italy as abroad, the natural risk due to hydrogeological catastrophes is a remarkable problem for the damages produced and for the number of victims (e.g. Messina 02/10/2009 and Ischia 10/11/2009). The realization of structural measures for the mitigation of hydrogeological risk is essential, because of the extreme diffusion of the problem and also to safeguard the people exposed. Detention reservoirs are structural measures for the defense from hydraulic risk. These works allow one to temporarily contain part of the flood volume and then return it, getting an attenuation and a delay of the peak discharge, proper to peak reduction phenomenon. A classical structural measure for the mitigation of the hydraulic risk is represented by the off-stream floodplain storage: areas near to water courses used as storage, escaping volumes of upcoming flood through devices of derivation as, for instance, weirs. In the present paper, the first results of an experimental survey on a physical model, situated in the Laboratory of Hydraulics of the Department of Hydraulic, Geotechnical and Environmental Engineering of University of Naples Federico II, of off-stream floodplain storage are shown.
\end{abstract}

Keywords: flood mitigation, hydrogeological risk, hydraulic engineering.

\section{Introduction}

The natural risk due to hydrogeological catastrophes in lowland areas can be extremely dangerous, particularly if floodplains are intensively exploited. In such areas floods can cause remarkable economic losses and even risk of deaths (Dunn and Deering [7]; Zhang et al. [12]). Given the high level of diffusion of 
this problem and in order to safeguard people at risk, the implementation of structural measures designed for risk mitigation is essential. Detention reservoirs are structural measures for the defense against hydraulic risk. Among these structural measures for flood risk reduction, an effective method is to build floodplain storage. Floodplain storage allows part of the flood volume to be temporarily stored, thus reducing the outflow discharge. When discharge falls below the maximum allowable flow, the flood volume is released back into the river. Design of off-stream floodplain storage for reducing flood risk has often been discussed in literature. Since storage areas are in general relatively flat, two- and three-dimensional numerical models can be applied in order to simulate floodplain storage accurately. Several two-dimensional flood models are available in literature; among these, Jaffe and Sanders [9] proposed a 2D backwater model reproducing the filling of off-stream floodplain storage after a levee breach occurrence. Beffa and Connell [3] describe a 2D finite element model, Hydro2de, later applied by Connell et al. [4] to simulate two floods on the Waihao River in New Zeland. Starting from the Monoclinal Flood Wave theory, Shome and Steffler [11] got a theoretical 2D model to estimate the flood wave velocity and the volume which is filling the storage. The authors applied the model to the simple case of a rectangular channel and linked the discharge filling the storage to its geometric features and bottom roughness. Adopting twodimensional models can generate difficulties (Freeman et al. [8]) in preliminary sizing of floodplain storages in relatively flat areas since they are data intensive and require advanced modelling capabilities. Consequently, it is often suggested to adopt simpler one-dimensional models, based on level pool reservoir (or uniform storage) hypothesis (McEnroe [10]; Basha [1, 2]). In this paper, the results of an experimental research on off-stream floodplain storage, by the use of a physical model, located in the Laboratory of Hydraulics of the Department of Hydraulic, Geotechnical and Environmental Engineering (DIGA) of the University of the Studies in Naples "Federico II", are discussed.

\section{Experimental setup}

The experimental setup was extensively described in De Paola et al. [6] and De Martino et al. [5] and a schematic view of the installation is shown in Figure 1. The installation is served by a hydraulic recirculation circuit internal to the Laboratory of Hydraulic of DIGA. It is made of: a stilling basin to dissipate energy and provide an accurate inflow discharge measurement using a rectangular weir; a $0.5 \%$ slope rectangular channel $h_{c}=0.50 \mathrm{~m}$ high and $\mathrm{B}=0.45 \mathrm{~m}$ wide. In the channel, a flood gate was fitted in order to produce flooding into the upstream channel, as well as an outflow tank in order to provide the flow intake into the laboratory hydraulic circuit. The total channel length was $35.60 \mathrm{~m}$. A side rectangular weir was assembled $0.60 \mathrm{~m}$ from the downstream flood gate with $p=0.38 \mathrm{~m}$ (Fig. 1). During the experiments, the length of the rectangular weir was initially fixed at $1.5 \mathrm{~m}$, and 36 tests were carried out with such dimension. Other tests, in progress, are with a rectangular weir length of $1 \mathrm{~m}$. 


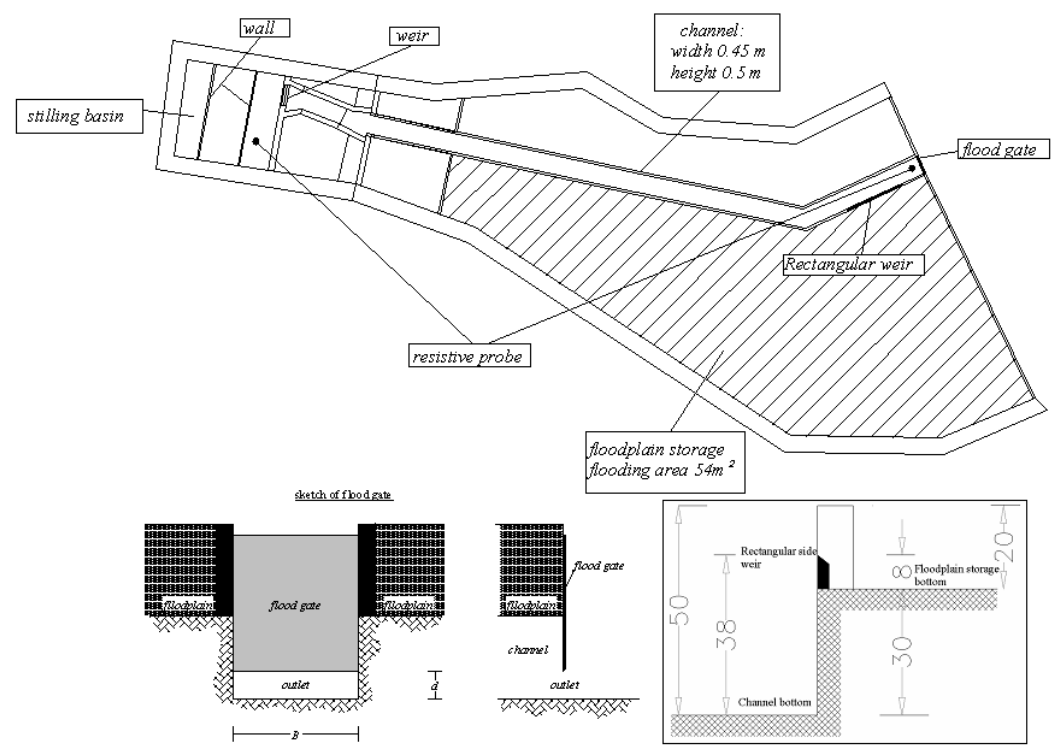

Figure 1: $\quad$ Experimental setup.

During the experiments, after the flow immission into the channel, water comes back because of the flood gate that leaves a free height of $\mathrm{d}=0.03 \mathrm{~m}$ and causes an increase of the water level $h$ in the channel. For $h$ bigger than $0.38 \mathrm{~m}$, the inundation of floodplain storage begins. This storage has a surface of about $54 \mathrm{sqm}$ and a circular outlet of $0.04 \mathrm{~m}$ diameter (Fig. 1).

During the tests, the inflow and outflow hydrographs were derived by using two resistive level probes, the first located in the stilling basin and the second near the flood gate and connected to a P.C. that allows one to record the $\Delta \mathrm{V}$ sequence in time (Fig. 1). By the probe positioned in the upstream stilling basin it is possible to record the hydraulic level on the weir and so to calculate the discharge with the following expression:

$$
Q_{i}(t)=\mu_{0} \cdot L \cdot \sqrt{2 g} \cdot \delta_{o}(t)^{3 / 2}
$$

where $Q_{i}(t)$ and $\delta_{0}(t)$ are respectively the inflow and the hydraulic level on the weir at time $\mathrm{t}$, while $\mu_{0}(=0.456)$ and $L$ are the discharge coefficient experimentally set and the length of the weir $(0.49 \mathrm{~m})$.

The inflow discharge was adjusted through a gate valve, in order to produce the wanted inflow hydrographs.

The flood gate allows the discharge to come back, thus causing the inundation on the floodplain storage as soon as the water level in the channel becomes higher than $\mathrm{h}_{\mathrm{rw}}=0.38 \mathrm{~m}$. 
For the evaluation of the outflow hydrographs, a second probe was positioned immediately upstream the flood gate that allows one to measure the water level in time. The outflow hydrograph has been calculated by the expression:

$$
Q_{u}(t)=\mu_{P} \cdot B \cdot d \cdot \sqrt{2 g \cdot\left(h(t)-\frac{d}{2}\right)}
$$

where $Q_{u}(t)$ and $h(t)$ are respectively the outflow discharge and the water surface level immediately upstream the gate at time $\mathrm{t}, \mu_{p}(=0.635)$ is the discharge coefficient of the flood gate, while $\mathrm{B}$ and $\mathrm{d}$ are, respectively, the width and the height of the outflow span equal respectively to $0.45 \mathrm{~m}$ and $0.03 \mathrm{~m}$.

According to the different test duration, two different behaviours of the lateral rectangular weir can be distinguished: free flow and submerged flow (with backwater effects).

The tests with submerged flow behaviour are characterized by a first phase in which the channel feeds the storage and a second phase, in which, since the water surface in the storage is bigger $\mathrm{z}$ than the weir height $\mathrm{h}$, the storage feeds the channel (Fig. 2(b)).

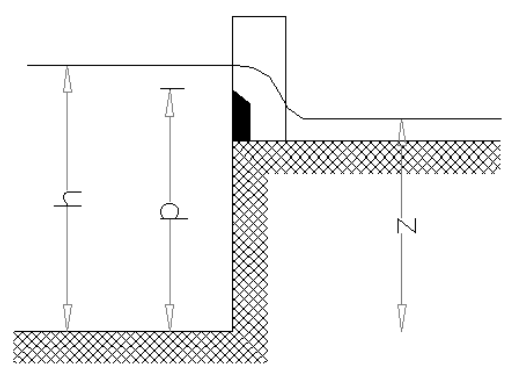

(a)

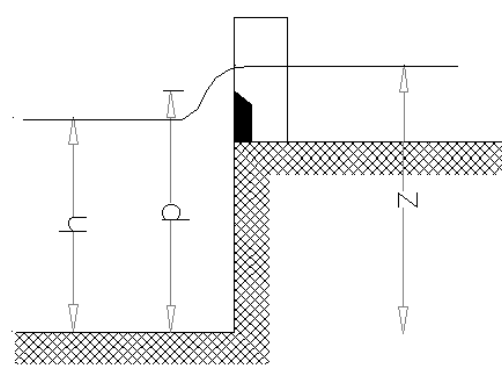

(b)

Figure 2: Definition of weir behaviour: (a) not submerged; (b) submerged.

In the tests characterized by the absence of the submerged behaviour, only the channel feeds the storage $(h>z)$, because the water level in the storage $\mathrm{z}$ does not overcome the weir height h (Fig. 2(a)).

The tests are divided into two groups of 36, the first one with a length of the rectangular weir of $1.5 \mathrm{~m}$, other tests, in progress, are with a length of $1 \mathrm{~m}$. Within every group, 18 tests are characterized by a submerged behaviour and 18 by the absence of any back water effect.

For every test the characteristic values are: test duration $t$, initial inflow discharge $Q_{o}$, peak discharge $Q_{\max }$, maximum outflow discharge $Q_{\text {out }}$, initial water surface $h_{o}$, peak water surface $h_{\max }$, peak reduction ratio $\eta=Q_{\text {out }} / Q_{\max }$, storage ratio $w$ (tables 1 and 2).

The result of every experimental test has been synthesized into two graphs: in the first one the inflow $Q i$ and outflow hydrographs $Q u$ (Fig. 3) are shown; in the second the water surface upstream $h u$ the floodgate (Fig. 4). 
Table 1: Characteristics of 18 tests without backwater effects.

\begin{tabular}{|c|c|c|c|c|c|c|c|c|c|}
\hline test & $\begin{array}{c}\text { date } \\
\text { (d/m/y) }\end{array}$ & $\begin{array}{c}\mathbf{t} \\
{[\mathbf{s e c}]}\end{array}$ & $\begin{array}{c}\text { Qo } \\
{[\mathrm{Ips}]}\end{array}$ & $\begin{array}{c}\text { Qmax } \\
{[\mathrm{Ips}]}\end{array}$ & $\begin{array}{c}\text { Qout } \\
{[\mathrm{lps}]}\end{array}$ & $\begin{array}{c}\mathbf{h}_{\mathbf{0}} \\
{[\mathrm{cm}]}\end{array}$ & $\begin{array}{c}\mathbf{h}_{\max } \\
{[\mathrm{cm}]}\end{array}$ & $\boldsymbol{\eta}$ & $\mathbf{w}$ \\
\hline 1 & $23 / 04 / 2009$ & 290 & 20.44 & 37.10 & 21.80 & 30.28 & 38.10 & 0.59 & 0.41 \\
\hline 2 & $24 / 04 / 2009$ & 200 & 22.33 & 61.40 & 25.70 & 35.40 & 47.10 & 0.42 & 0.55 \\
\hline 3 & $24 / 04 / 2009$ & 150 & 22.73 & 68.33 & 25.83 & 35.70 & 47.70 & 0.38 & 0.55 \\
\hline 4 & $12 / 05 / 2009$ & 160 & 23.83 & 49.80 & 24.60 & 36.30 & 43.58 & 0.49 & 0.45 \\
\hline 5 & $12 / 05 / 2009$ & 170 & 21.00 & 54.90 & 24.80 & 32.90 & 44.09 & 0.45 & 0.51 \\
\hline 6 & $12 / 05 / 2009$ & 180 & 21.70 & 59.70 & 25.00 & 33.30 & 44.80 & 0.42 & 0.54 \\
\hline 7 & $12 / 05 / 2009$ & 170 & 21.16 & 63.40 & 25.10 & 33.50 & 45.40 & 0.40 & 0.56 \\
\hline 8 & $15 / 05 / 2009$ & 170 & 21.60 & 56.30 & 24.50 & 32.40 & 43.00 & 0.44 & 0.52 \\
\hline 9 & $15 / 05 / 2009$ & 160 & 22.40 & 62.20 & 24.80 & 32.07 & 44.04 & 0.40 & 0.55 \\
\hline 10 & $15 / 05 / 2009$ & 160 & 22.05 & 65.40 & 25.00 & 32.80 & 44.70 & 0.38 & 0.57 \\
\hline 11 & $15 / 05 / 2009$ & 160 & 22.20 & 68.35 & 25.10 & 33.20 & 45.20 & 0.37 & 0.58 \\
\hline 12 & $21 / 05 / 2009$ & 180 & 24.20 & 51.90 & 25.20 & 38.30 & 45.70 & 0.49 & 0.44 \\
\hline 13 & $21 / 05 / 2009$ & 170 & 22.60 & 58.70 & 25.50 & 35.70 & 46.50 & 0.43 & 0.53 \\
\hline 14 & $21 / 05 / 2009$ & 160 & 22.90 & 64.30 & 25.70 & 35.80 & 47.20 & 0.40 & 0.56 \\
\hline 15 & $21 / 05 / 2009$ & 170 & 23.30 & 67.60 & 25.80 & 36.30 & 47.70 & 0.38 & 0.57 \\
\hline 16 & $29 / 05 / 2009$ & 200 & 22.05 & 47.10 & 24.70 & 35.00 & 43.80 & 0.52 & 0.44 \\
\hline 17 & $29 / 05 / 2009$ & 180 & 21.50 & 53.80 & 24.90 & 33.10 & 44.50 & 0.46 & 0.49 \\
\hline 18 & $29 / 05 / 2009$ & 170 & 21.40 & 58.40 & 25.40 & 35.00 & 46.30 & 0.43 & 0.52 \\
\hline
\end{tabular}

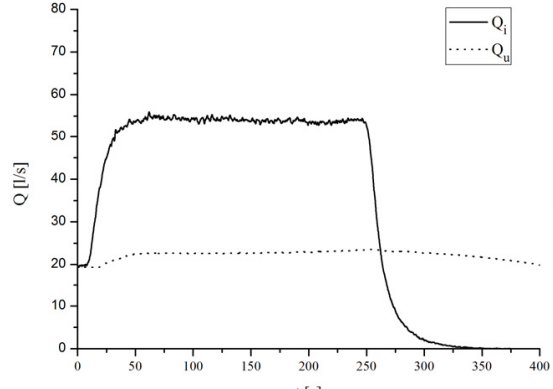

(a)

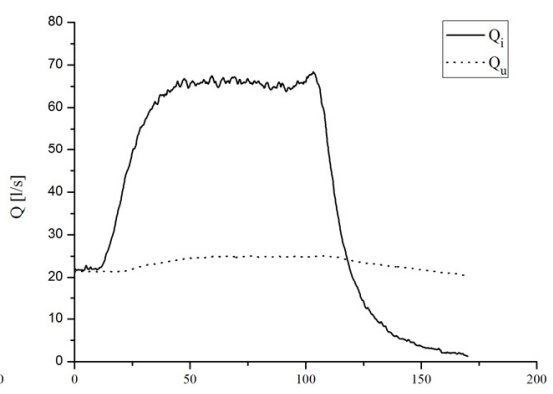

(b)

Figure 3: Inflow and outflow hydrographs for the two different behaviours (submerged (a) and not (b)) of the rectangular weir. 
Table 2: $\quad$ Characteristics of 18 tests with submerged flow behaviour.

\begin{tabular}{|c|c|c|c|c|c|c|c|c|c|}
\hline test & $\begin{array}{c}\text { date } \\
(\mathbf{d} / \mathbf{m} / \mathbf{y})\end{array}$ & $\begin{array}{c}\mathbf{t} \\
{[\mathbf{s e c}]}\end{array}$ & $\begin{array}{c}\mathbf{Q}_{\mathbf{o}} \\
{[\mathbf{l p s}]}\end{array}$ & $\begin{array}{c}\mathbf{Q}_{\max } \\
{[\mathbf{l p s}]}\end{array}$ & $\begin{array}{c}\text { Qout } \\
{[\mathbf{l p s}]}\end{array}$ & $\begin{array}{c}\mathbf{h o} \\
{[\mathbf{c m}]}\end{array}$ & $\begin{array}{c}\mathbf{h} \max \\
{[\mathbf{c m}]}\end{array}$ & $\boldsymbol{\eta}$ & $\mathbf{w}$ \\
\hline 1 & $29 / 05 / 2009$ & 380 & 21.60 & 58.3 & 24.50 & 33.35 & 44.30 & 0.42 & 0.55 \\
\hline 2 & $05 / 06 / 2009$ & 450 & 21.06 & 52.7 & 24.50 & 30.80 & 43.22 & 0.46 & 0.53 \\
\hline 3 & $05 / 06 / 2009$ & 410 & 20.20 & 59.9 & 24.70 & 29.99 & 43.75 & 0.41 & 0.58 \\
\hline 4 & $05 / 06 / 2009$ & 380 & 20.22 & 56.1 & 25.20 & 31.55 & 45.70 & 0.45 & 0.54 \\
\hline 5 & $05 / 06 / 2009$ & 390 & 20.60 & 65.4 & 24.70 & 30.34 & 43.70 & 0.38 & 0.60 \\
\hline 6 & $05 / 06 / 2009$ & 390 & 20.50 & 66.7 & 24.65 & 30.50 & 43.67 & 0.37 & 0.61 \\
\hline 7 & $17 / 06 / 2009$ & 460 & 20.20 & 52.3 & 24.60 & 30.00 & 43.65 & 0.47 & 0.53 \\
\hline 8 & $17 / 06 / 2009$ & 470 & 20.02 & 56.3 & 24.80 & 29.60 & 44.15 & 0.44 & 0.55 \\
\hline 9 & $17 / 06 / 2009$ & 460 & 20.04 & 59.8 & 24.76 & 30.30 & 44.03 & 0.41 & 0.58 \\
\hline 10 & $18 / 06 / 2009$ & 390 & 20.60 & 52.7 & 23.80 & 30.10 & 40.80 & 0.45 & 0.53 \\
\hline 11 & $18 / 06 / 2009$ & 400 & 20.40 & 56.3 & 24.16 & 29.40 & 42.00 & 0.43 & 0.56 \\
\hline 12 & $18 / 06 / 2009$ & 360 & 20.14 & 60.3 & 24.15 & 29.50 & 41.95 & 0.40 & 0.58 \\
\hline 13 & $18 / 06 / 2009$ & 400 & 19.90 & 62.3 & 24.60 & 29.50 & 43.50 & 0.39 & 0.60 \\
\hline 14 & $18 / 06 / 2009$ & 370 & 19.94 & 64.3 & 24.50 & 29.10 & 43.00 & 0.38 & 0.60 \\
\hline 15 & $14 / 07 / 2009$ & 390 & 19.95 & 51.6 & 23.30 & 28.10 & 39.20 & 0.45 & 0.52 \\
\hline 16 & $14 / 07 / 2009$ & 390 & 19.80 & 55.4 & 23.40 & 27.30 & 39.60 & 0.42 & 0.54 \\
\hline 17 & $14 / 07 / 2009$ & 400 & 19.50 & 61.6 & 23.93 & 27.52 & 41.20 & 0.39 & 0.60 \\
\hline 18 & $14 / 07 / 2009$ & 400 & 19.59 & 55.9 & 23.60 & 27.33 & 40.00 & 0.42 & 0.56 \\
\hline & & & & & & & & & \\
\hline
\end{tabular}

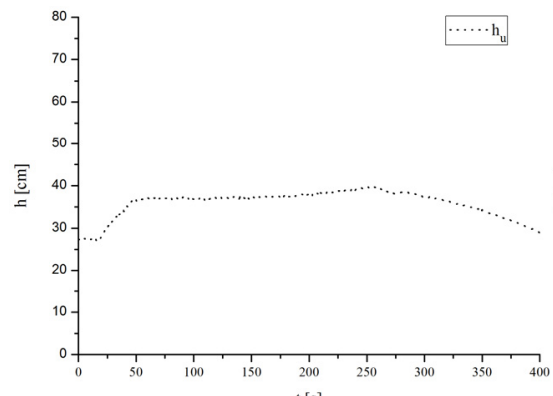

(a)

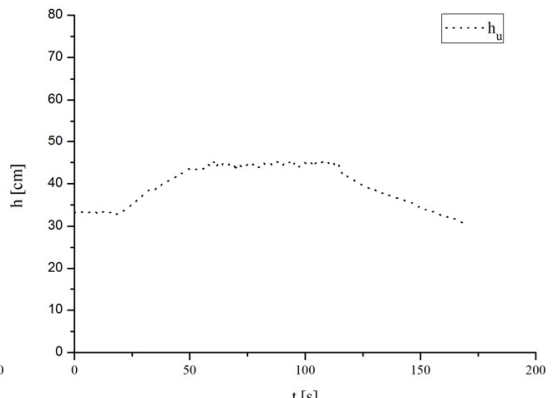

(b)

Figure 4: Water surface level upstream of the floodgate for the two different behaviours (submerged (a) and not (b)) of the rectangular weir. 
The experimental results have been analyzed, focusing on the efficiency of the off-stream storage under the different conditions of operation examined and appraising the peak reduction ratio

$$
\eta=\frac{Q_{\text {out }}}{Q_{\max }} .
$$

The storage ratio is equal to

$$
w=\frac{W_{S}}{W_{f}},
$$

which means equal to the ratio between the portion of inclusive area among the inflow and outflow hydrographs, starting from the point of intersection between the two curves (it represents the water volume contained in storage $\mathrm{W}_{\mathrm{s}}$ ) and the portion of graph under the inflow hydrograph (it represents the flood volume $\mathrm{W}_{\mathrm{f}}$ ) (Fig. 5).

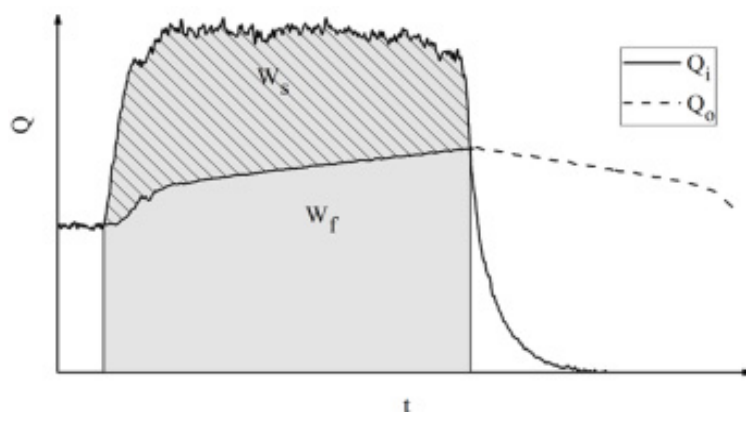

Figure 5: $\quad$ Evaluation of the volumes $\mathrm{W}_{\mathrm{s}}$ and $\mathrm{W}_{\mathrm{f}}$ : schematic sketch.

In all the analyzed configurations, any increase of the storage ratio corresponds to a reduction of the peak reduction $\eta$, and, consequently, of outflow discharge (Fig. 6).

From the comparison among the two groups of tests (those characterized by either out flowed or not out flowed behaviour (Fig. 6)) it is possible to observe that the submerged behaviour gives place to slightly greater volumes in comparison to the not submerged behaviour of weir. After the flooding, there are, in fact, inside the storage, wider water surfaces. Such an aspect must be taken into account in the design phase, since bigger embankment heights are planned.

The peak reduction ratio has been correlated to the peak discharge $\mathrm{Q}_{\max }$ (Fig. 7), that is the flow corresponding to the flood peak in every test. To increase the peak discharge of water, the peak reduction ratio of the storage allows one to reduce it for all the adopted experimental configurations. 


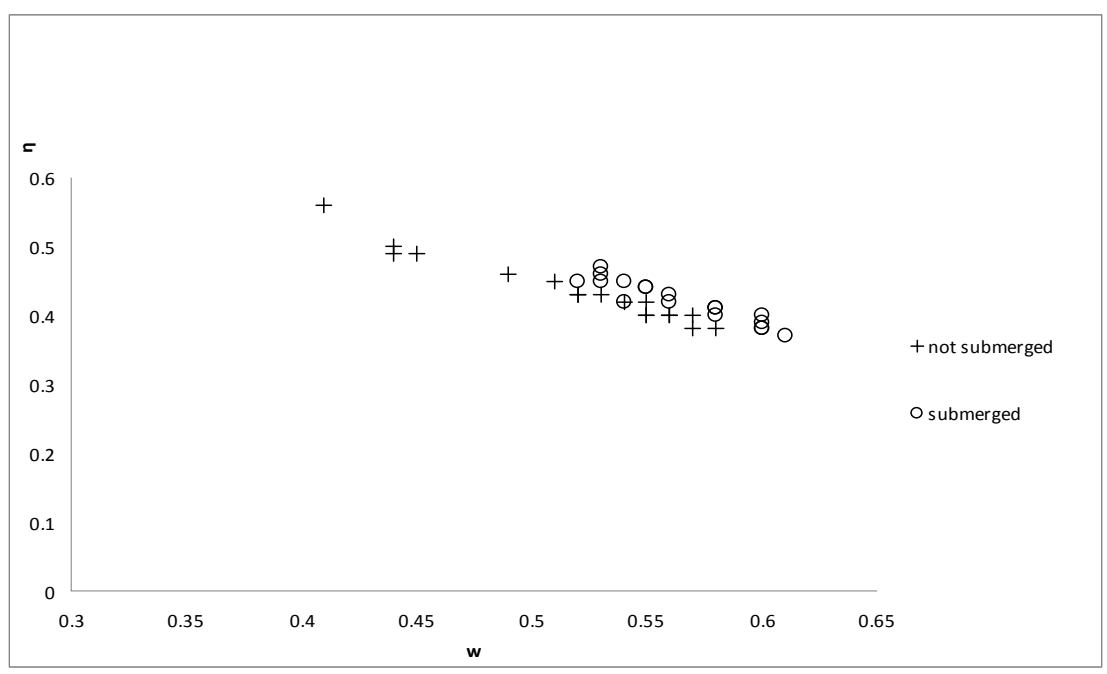

Figure 6: Comparison among peak reduction ratio - storage ratio.

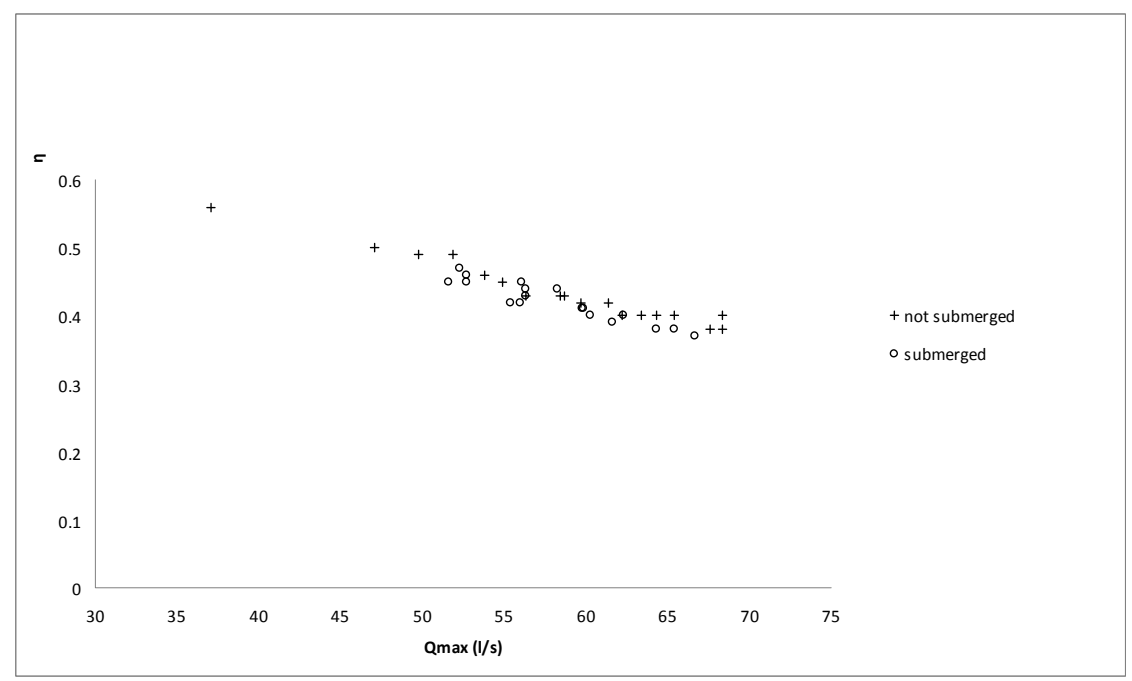

Figure 7: Peak reduction ratio vs. peak discharge.

\section{Conclusive remarks}

In the present study, experimental results on off-stream floodplain storages are discussed. The analyses carried out on the physical model have shown:

- by increasing the maximum capacity the peak reduction ratio $\eta$ decreases, and so an improvement of the efficiency of the floodplain storage is evidenced; 
- the submerged behaviour of the rectangular side weir allows to flood in the storage a water volume greater respect of not submerged behaviour, because of the bigger water levels in the storage. So, during the design of the embankments, it is necessary to calculate bigger heights;

- the tests for off-stream floodplain storages have supplied inferior values of $\eta$ and greater values of $\mathrm{w}$ in comparison with a previous experimental survey on on-line floodplain storages, evidencing, therefore, more elevated efficiency of off-stream ones.

The purpose of the authors is to compare the results obtained experimentally with those obtained by numerical one-dimensional and two-dimensional models that are in progress.

\section{References}

[1] Basha, H. A. (1994). "Non linear reservoir routing: a particular analytical solution", J. of Hydraulic Engineering, 120(5), 624-632

[2] Basha, H. A. (1995). "Routing Equations for Detention Reservoirs", J. of Hydraulic Engineering, 121(12), 885-888

[3] Beffa, C., and Connell, R. J. (2001). "Two-Dimensional Flood Plain Flow. I: Model Description" J. of Hydrologic Engineering, 6(5), 397-405

[4] Connell, R. J., Painter, D. J., and Beffa, C. (2001). "Two-Dimensional Flood Plain Flow. II: Model Validation" J. of Hydrologic Engineering, 6(5), 406-415

[5] De Martino, G., De Paola, F., Marini, G., and Ranucci, A (2007). "Onstream floodplain storages: experimental research" Proc., Thirteenth International Conference on Computational Methods and Experimental Measurements, Prague, Chez Republic, 307-317

[6] De Paola, F., Fontana, N., and Ranucci, A. (2006). "Indagine sperimentale per la verifica del comportamento idraulico di casse di espansione in linea" Proc., XXX Convegno di Idraulica e Costruzioni Idrauliche, Roma, Italy, 110

[7] Dunn C. \& Deering M. (2009). "Flood Risk Assessment of Complex Riverine Systems" World Environmental and Water Resources Congress 2009: Great Rivers. Proceedings of the World Environmental and Water Resources Congress 2009.

[8] Freeman, G. E., Sundararaghavan, H., and Heyen, J. (2003). "TwoDimensional Modeling of Floodplains. - Necessary or Excessive? Two Case Studies" Proc., World Water Congress 2003, 118-140

[9] Jaffe, D. A., and Sanders, B. F. (2001). "Engineered Levee Breaches for Flood Mitigation" J. of Hydraulic Engineering, 127(6), 471-479

[10] McEnroe, B. M. (1992). "Preliminary sizing of detention reservoirs to reduce peak discharges" J. of Hydraulic Engineering, 118(11), 1540-1549

[11] Shome, M. L., and Steffler, P. M. (2006). "Flood Plain Filling by a Monoclinal Flood Wave" J. of Hydraulic Engineering, 132(5), 529-532 
PI-654 Risk Analysis VII

[12] Zhang X., Zhang W., Qiu S., and Zhang R. L. (2008). "Research on Integrated Flooding Risks and Flooding Risk Mapping", World Environmental and Water Resources Congress 2008: Ahupua'a. Proceedings of the World Environmental and Water Resources Congress 2008. 